\title{
SHOULDER ASSESSMENT AND TREATMENT ACCORDING TO CYRIAX
}

\author{
DOROTHY SWEATMAN, M.C.S.P. and Member Society of Orthopaedic Medicine*
}

\section{SUMMARY}

If correct diagnosis of the shoulder joint is made true and cffective, treatment can be carried out by physiolherapy, in conjunction with a medical practitioner.

\section{THE SHOULDER}

The shoulder is the most rewarding joint to treat in the whole body. Once the lesion has been identified, there is no joint in the body that responds so well and so quickly to treatment. Many different lesions exist but they can all be clistinguished; identification is merely an exercise in applied anatomy. The assessment is purely clinical, the physiotherapist testing the function of each relevant tissue in turn. Difficult cases do exist, such as perhaps a double lesion, or a pattern hard to interpret. In general it is best to treat the joint first, since signs thought to incriminate some other tissue often disappear as the joint recovers. Tendinous and capsular lesions at the shoulder are quite separate and each may be present for years without affecting the other, and they do not merge together.

Tcndinous lesions themselves do not limit the movement at the shoulder. Limitation of active movement can. of course, be due to supraspinatus tendinitis, so painful that an arc exists which prevents the patient from raising his arm above the horizontal by his own efforts. But full passive elevation relaxes the supraspinatus muscle and the arm can be raised without pain. Hence, tendinous lesions do not limit the passive range of movcment and it is the passive movement, not the active, that informs the examiner what the true range is.

\section{REFERRED PAIN}

Pain is referred on a segmental basis. Symptoms arising from the tissues at the shoulder are seldom felt at the shoulder itself, the exception being the acromioclavicular joint as it is developed within the fourth cervical segment and cannot therefore refer pain to the arm. All other common lesions at the shoulder affect structures derived largely from the fif th cervical segment, hence the pair is felt to start in the lower deltoid area and to spread along the relevant dermatone which ends at the radial side of the wrist.

Pain indicates two things:

- it outlines the dermatone and shows the segment which has the lesion and

- it indicates the severity of the lesion.

The more severe the lesion the more extensive the reference of pain.

Lesions can occur in any of the following structures at the shoulder:

- Capsule of the shoulder joint (C5).

- Subdeltoid bursa (C4).

- Acromioclavicular joint (C4).

- Supraspinatus tendon (C5).

- Infraspinatus tendon (C5/C6).

- Subscapular tendon (C5/C6).

* Private Practitioner. Cape Town.

Received 15 February 1982.

\section{OPSOMMING}

As diagnose van die skouer suiwer en effektief gemaak word. kan behandeling deur fisioterapie, in samewerking met ' $n$ mediese praktisyn, uitgevoer word.

- Long head of biceps (C5/C6).

- Bone

There is also the possibility of pain being referred to the shoulder from the neck or the diaphragm (C4).

Bone disease, a fracture, or a tumour present little diagnostic difficulty since the pattern indicating one tissue or another at the shoulder is noticeably absent and the radiograph discloses the reason. By contrast the capsule of the shoulder joint, the bursae and the tendons are all radiotranslucent; hence the X-ray of a painful shoulder usually reveals no abnormality.

Most patients with a painful shoulder are middle-aged. A narrow joint space or an osteophyte is bound to be seen on the X-ray of the cervical spine and the tendency is to treat what is showing on the X-ray and not the real lesion. It is common to see cases in which months of treatment have been given in vain to symptomless spondylosis at the neck, ignoring the painful shoulder. Whether the pain at the shoulder results from a local lesion or is referred, can only be determined by a clinical examination.

\section{EXAMINATION AT THE SHOULDER}

The history is important in diagnosis and selecting treatment. Questions must be asked as the answers will help to determine the stage that the lesion has reached - but if a tendon is found to be injured, none of the points raised in the history are relevant.

\section{NINE QUESTIONS}

- Where is the pain? If at the shoulder, the acromioclavicular joint is suggested. Pain in the arm, on the other hand, is common to all other lesions.

- Was there any injury? If a capsular pattern is found, this suggests traumatic arthritis.

- What is the patient's age? Relevant to distinguish the different types of arthritis.

- How long has it been present? If a capsular pattern is present, this indicates an arthritis.

- Have any other joints been affected? If affirmative answer, this suggests rheumatoid or ankylosing spondylitis.

- Has the pain spread? The more the pain goes down the arm, the more severe the lesion.

- Can the patient lie on that side at night? If not, and the capsular pattern is present, then treatment by forcing movement is inappropriate.

- Is there pain by day even when the arm is kept still? lf so, forcing is again contraindicated.

- Has surgery ever been performed? Relevant if the pattern for malignant invasion at the shoulder emerges.

A complaint of pain in the scapular area and/or arm indicates a lesion in a tissue forming part of the C4 - T2 segments. The first approach therefore is a quick review of all these segments from neck to fingers. This preliminary check could indicate that: 
- There is something the matter with the shoulder or

- A lesion exists but does not lie at the shoulder or

- No lesion of a moving part exists but the patient is sincere, drawing attention to visceral disease, such as angina or pulmonary sulcus tumour or

- There is neurosis on the basis of multiple inconsistencies. The examiner must note range of movement and power.

The capsular pallern at the shoulder is that of much limitation of abduction, more limitation of lateral rotation and less limitation of medial rotation.

Table 1 shows different degrees of severity in this pattern.

TABLE 1

\begin{tabular}{lccc}
\hline & Capsular & \multicolumn{2}{c}{ Proportions } \\
\hline & Abduction & $\begin{array}{c}\text { Lateral } \\
\text { rotation } \\
\text { limited by }\end{array}$ & $\begin{array}{c}\text { Medial } \\
\text { rotation } \\
\text { limited by }\end{array}$ \\
Arthritis & $10^{\circ}$ & $30^{\circ}$ & $\begin{array}{c}\text { Painful at } \\
\text { Slight }\end{array}$ \\
Moderate & $45^{\circ}$ & $70^{\circ}$ & full range \\
Severe & $70^{\circ}$ & $100^{\circ}$ & $10^{\circ}$ \\
& & & $20^{\circ}$
\end{tabular}

The capsular pattern of limited movement indicates arthrit is whether or not radiography discloses any abnormality.

At every joint in the body supported by muscles, capsular contracture takes place in a characteristic way and has its individual capsular pattern. Whatever the nature of the arthritis, clinical examination will reveal limitation of range in the capsular proportions. The symptoms and end-feel indicate what stage the arthritis has reached.

At the shoulder joint there are three common types of arthritis, viz. traumatic arthritis, monarticular rheumatoid arthritis and osteoarthrosis. There is an unfortunate tendency to lump them all together under one blunderbuss label namely "frozen shoulder", and this is no help as it does not indicate the cause, nor which tissue of the joint is affected. Since all the structures around the shoulder have a name, the diagnosis should be specific.

The physical signs fall into four main categories:

- Limited passive movement - capsular pattern.

- Limited passive movement - non-capsular pattern.

- Full passive range, one resisted movement hurts tendinous lesions.

- Full passive range - one or more muscles are weak.

\section{CLINICAL EXAMINATION}

Twelve movements are carried out. The examiner notes range and power. The patient must report the presence or absence of pain. If any movement hurts, he must indicate where it is felt, and if it is his specific pain or an unconnected ache.

NECK

Active flexion, extension, side flexion to

SCAPULA

SHOULDER

ELBOW

both sides, and rotation to both sides.

Active elevation (C3/C4).

Active elevation (C5).

Resisted flexion (C5/C6); resisted extension (C7).

WRIST Resisted extension (C6); resisted flexion (C7).

THUMB Resisted extension (C8); resisted adduction (C8).

FIFTH FINGER Resisted adduction (T1).

If this survey makes it clear that the shoulder is at fault, then the shoulder is examined in detail by using twelve movements.

\section{The Twelve Movements are}

\section{- Active elevalion}

The patient is asked to bring his arm up as high as he can. The range of abduction at the shoulder is $90^{\circ}$, whereupon the tuberosity engages against the edge of the glenoid fossa. The next $60^{\circ}$ of elevation is brought about by active rotation of the scapula. but when the arm has reached the vertical the last $30^{\circ}$ of elevation consists of adduction of the humerus across the front of the scapula, now possible because the coracoid and acromion processes point upwards instead of forwards.

Passive elevarion

The examiner pushes the arm up as high as it will go and notes:

- The range of elevation.

- Does it correspond with the active range.

- Whether pain is provoked or not.

- The end-feel. Whether the movement comes to a hard or a soft stop at the extreme of range; this has considerablc diagnostic significance.

\section{Painful arc}

The patient is again asked to bring his arm up and to say when the pain begins and ends. Pain is evoked as the arm passes the horizontal, but is absent before and after, thus a painful arc is present and it indicates that the tender tissue lies in a position where it can be pinched between the acromion and the tuberosity. The four tissues involved are supraspinatus, infraspinatus, subscapular tendon or the subdeltoid bursa.

Three passive movements are carried out to determine the amount of movement permitted by the capsule of the shoulder joint

\section{Passive scapulohumeral abduction}

With the thumb of one hand fixing the lower angle of the scapula, the examiner uses his other hand to elevate the arm until he feels the scapula begin to rotate. The normal range is $90^{\circ}$.

\section{Passive lateral rotation}

The examiner bends the patient's elbow to a right angle and using the forearm as a lever rotating it outwards. The normal range is $90^{\circ}$.

\section{Passive medial rotation}

The examiner rotates the humerus and notes how far behind the patient's back the forearm can be rotated. The normal range is $90^{\circ}$.

Now six resisted movements are carried out, one for each group of muscles in the shoulder region. The examiner must apply strong counter-pressure so that the joint itself does not move.

\section{Resisled abduction}

This tests the deltoid and the supraspinatus muscles, but as painful lesions of the deltoid do not occur, pain on resisted abduction indicates the supraspinatus.

\section{Resisted medial rotation}

This tests the pectoralis major, teres major, latissimus dorsi, and subscapularis muscles. Since the main function of the first three muscles is adduction, the subscapularis tendon is singled out if adduction is painless. 


\section{Resisted lateral rotation}

This tests the infraspinatus and teres minor muscles. The latter is an adductor of the humerus. If lateral rotation alone hurts, attention is drawn to the infraspinatus tendon.

Resisted adduction

This tests the thoraco-humeral muscles.

Resisted flexion at the elbow

This tests the biceps and brachialis muscles; if resisted supination also hurts, there is a lesion of the biceps.

Resisted extension at the elbow

This tests the triceps.

\section{RADIOGRAPHY}

Interpretation of the pattern that emerges, and the responses, when the twelve movements are tested, enables the examiner to determine the lesion present. Only now it is safe to look at the X-ray photograph. Fracture, neoplasm, tuberculosis and osteitis deformans are revealed if present. A small patch of calcification or an osteophyte may be seen, but it does not follow that either is relevant to the patient's symptoms. In the ordinary cases of arthritis, bursitis, or tendinitis it is usual for no abnormality to be detectable on $\mathrm{X}$ ray.

\section{TREATMENT}

Treatment at the shoulder is very effective as long as the correct diagnosis has been made. Most of the lesions respond excellently to deep cross friction massage, or injection of a steroid suspension and some of them require stretching by the physiotherapist.

The intentions are:

- Restoration of a painless range of movement

- Restoration of painless function to a tendon

- Abolition of bursal inflammation

\section{Restoration of Painless Range}

\section{Traumatic arthritis}

If treated in the early stages it can be aborted by stretching by a physiotherapist if the patient presents with the following criteria:

- A short history.

- No pain except on movement.

- The ability to lie on that side.

- No pain below the elbow.

- Elastic end feel.

If the criteria indicate that the lesion has become too acute for stretching, the physiotherapist can achieve good results by distraction techniques, viz. passively drawing the head of the humerus away from the glenoid.

\section{Monarticular rheumatoid arthritis}

The response to intra-articular steroid injection is immediate and no other treatment is worth using.

\section{Osteoarthrosis}

The contracture caused by osteoarthrosis requires stretching by the physiotherapist. Steroid injection here is useless.

\section{Restoration of Painless Function to a Tendon}

A scar in a short tendon can be made to transmit muscle pull painlessly. By using deep cross friction massage to the exact site of the scar, it is broken up mechanically. The whole length of the scar must be treated. It is a painful treatment but very effective and successful. The tendon can also be infiltrated with a steroid suspension.

\section{Abolition of Bursal Inflammation}

Acute bursitis

An attack of acute bursitis can be aborted by infiltrating the entire bursa with a steroid suspension.

\section{Chronic bursitis}

The infiltration with a local anaesthetic solution or steroid is very effective.

\section{TENDINOUS LESIONS}

These are common at the shoulder but it is no help to say merely that the rotator cuff is at fault - the specific part of the cuff must be determined. This is not difficult since each possess a separate function. The affected part of the tendon must be singled out by accessory tests.

Two criteria must be present before tendinitis can confidently be diagnosed:

- A full range of passive movement must exist at the shoulder joint. It is mechanically impossible for a painful tendon to interfere with the range of passive movement but it may cause pain when squeezed under the acromion or at the extreme of range, i.e. the movement may hurt at full range, but the range is full and the end feel is soft.

- Testing one group of muscles against resistance hurts, but testing the other groups provokes no discomfort. Accessory tests are employed to determine which member of that group is at fault and if possible which part of it.

\section{MUSCLE WEAKNESS}

When a full range of passive movement is found, but a resisted movement is weak, the cause is either a nerve lesion or a tendinous rupture.

\section{CONCLUSION}

Some people consider a painful shoulder difficult to correct - this mistaken belief condemns thousands of people to months of unnecessary pain and disablement. Once the lesion has been identified by assessment, which is purely clinical, all that is needed is a good doctor and a competent physiotherapist working together. The only equipment required are hands, or syringe and needles, to secure long lasting relief from pain for the patient.

\section{Reference}

Cyriax, J. (1978). Textbook of Orthopaedic Medicine. Vol. 1. 7 th Ed. Baillière Tindall. London. 